\title{
Daily home-based spirometry during withdrawal of inhaled corticosteroid in severe to very severe chronic obstructive pulmonary disease
}

This article was published in the following Dove Press journal:

International Journal of COPD

22 August 2016

Number of times this article has been viewed

Roberto Rodriguez-Roisin'

Kay Tetzlaff ${ }^{2,3}$

Henrik Watz ${ }^{4}$

Emiel FM Wouters ${ }^{5}$

Bernd Disse ${ }^{2}$

Helen Finnigan ${ }^{6}$

Helgo Magnussen ${ }^{4}$

Peter MA Calverley ${ }^{7}$

'Respiratory Institute, Servei de Pneumologia, Hospital Clínic IDIBAPS-CIBERES, Universitat de Barcelona, Barcelona, Spain; ${ }^{2}$ Boehringer Ingelheim Pharma GmbH \& Co. KG, Ingelheim, Germany; ${ }^{3}$ Department of Sports Medicine, University of Tübingen, Tübingen, Germany; ${ }^{4}$ Pulmonary Research Institute at Lung Clinic Grosshansdorf, Airway Research Center North, German Center for Lung Research, Grosshansdorf, Germany; ${ }^{5}$ Department of Respiratory Medicine, University Hospital Maastricht, Maastricht University, Maastricht, the Netherlands; ${ }^{6}$ Department of Biostatistics and Data Sciences, Boehringer Ingelheim, Bracknell, UK; ${ }^{7}$ Institute of Ageing and Chronic Disease, Aintree University Hospital, Liverpool, UK

Correspondence: Roberto RodriguezRoisin

Respiratory Institute, Servei de Pneumologia, Hospital Clínic IDIBAPSCIBERES, Universitat de Barcelona, Villarroel, 170, 08036 Barcelona, Spain Tel +34932275404 Email rororo@clinic.ub.es
Abstract: The WISDOM study (NCT00975195) reported a change in lung function following withdrawal of fluticasone propionate in patients with severe to very severe COPD treated with tiotropium and salmeterol. However, little is known about the validity of homebased spirometry measurements of lung function in COPD. Therefore, as part of this study, following suitable training, patients recorded daily home-based spirometry measurements in addition to undergoing periodic in-clinic spirometric testing throughout the study duration. We subsequently determined the validity of home-based spirometry for detecting changes in lung function by comparing in-clinic and home-based forced expiratory volume in 1 second in patients who underwent stepwise fluticasone propionate withdrawal over 12 weeks versus patients remaining on fluticasone propionate for 52 weeks. Bland-Altman analysis of these data confirmed good agreement between in-clinic and home-based measurements, both across all visits and at the individual visits at study weeks $6,12,18$, and 52 . There was a measurable difference between the forced expiratory volume in 1 second values recorded at home and in the clinic (mean difference of $-0.05 \mathrm{~L}$ ), which may be due to suboptimal patient effort in performing unsupervised recordings. However, this difference remained consistent over time. Overall, these data demonstrate that home-based and in-clinic spirometric measurements were equally valid and reliable for assessing lung function in patients with COPD, and suggest that home-based spirometry may be a useful tool to facilitate analysis of changes in lung function on a day-to-day basis.

Keywords: $\mathrm{FEV}_{1}$, home-based spirometry, inhaled corticosteroid, lung function, severe COPD

\section{Introduction}

Lung function, measured at prespecified clinic visits, is a well-established outcome used to measure the effects of treatment interventions in clinical trials. Nonetheless, there are several inherent limitations to this approach, such as the restriction of the laboratory setting and it only offering a snapshot of lung function on set days of a trial. While this is useful to look at lung function in terms of overall change during a clinical trial, such information is limited if more detail on how lung function changes over time is required, and it is often not feasible to ask a patient to return to the clinic weekly, let alone daily. As part of the WISDOM (Withdrawal of Inhaled Steroids During Optimized bronchodilator Management, NCT00975195) study protocol, patients with severe to very severe COPD were asked to perform spirometry at home each day using a calibrated hand-held spirometer that had previously been used in the PLATINO (Proyecto Latino-Americano de Investigación en Obstrucción Pulmonar) 
and BOLD (Burden of Obstructive Lung Disease) ${ }^{2}$ studies. The WISDOM study demonstrated that inhaled corticosteroid (ICS) treatment can be stopped without increasing the risk of a subsequent exacerbation when effective background dual bronchodilator therapy is used. ${ }^{3}$ However, small but statistically significant differences in forced expiratory volume in 1 second $\left(\mathrm{FEV}_{1}\right)$ measured during clinic visits between the two arms were recorded, which merited further investigation.

Home-based spirometry is seldom used in clinical trials because $\mathrm{FEV}_{1}$ measured in-clinic is the lung-function end point required, but it is sometimes included as a secondary end point or as a primary measure in exploratory studies, ${ }^{4,5}$ especially in the early stages of drug development. Improvements in technology have led to the development of spirometers that provide reliable data without the need for daily calibration. As these devices capture both the time and quality of the expiratory maneuver, they can provide a reliable record of day-to-day lung-function variation not reflected in measurements taken at prefixed periodic clinic visits. However, in large clinical trials to date, little attention has been paid to how well the results of home-based spirometry recorded in parallel in this fashion relate to clinic spirometry performed under the supervision of trained technicians, particularly during longer periods of observation. ${ }^{6-8}$

In this study, we aimed to validate the use of weekly mean $\mathrm{FEV}_{1}$ data derived from home-based spirometry compared with data obtained in the clinic. Analysis of the weekly mean $\mathrm{FEV}_{1}$ data derived from home-based spirometry recordings would facilitate detailed study of the time course of lungfunction changes after ICS withdrawal in WISDOM, and specifically whether lung function continued to deteriorate over time after ICS withdrawal.

\section{Methods}

\section{WISDOM study design}

The WISDOM study methodology and results have been published previously. ${ }^{3,9}$ Briefly, patients with severe to very severe COPD $\left(\mathrm{FEV}_{1}<50 \%\right.$ predicted and $\mathrm{FEV}_{1}<70 \%$ of forced vital capacity $[\mathrm{FVC}]$ ) were recruited and, following a 6-week run-in on long-acting $\beta_{2}$-agonist/long-acting muscarinic antagonist/ICS (salmeterol/tiotropium/fluticasone propionate) treatment, were randomized (study week 0) to either continue this treatment or discontinue ICS in a stepwise manner over 12 weeks.

Predefined end points included changes from baseline in trough $\mathrm{FEV}_{1}$ (measured in-clinic) and weekly mean $\mathrm{FEV}_{1}$, FVC, and peak expiratory flow rate (PEFR) as measured by home-based spirometry. In-clinic lung function was assessed postbronchodilator at the screening visit before randomization (patients were allowed to take their normal medication on the morning of the screening visit) and prebronchodilator as a baseline value at the randomization visit (study week 0), when the first step-down in ICS dose from 500 to $250 \mu \mathrm{g}$ twice daily took place in the group randomized to ICS discontinuation. Further clinic measurements were performed at the time of the second ICS step-down from fluticasone propionate 250 to $100 \mu \mathrm{g}$ twice daily (study week 6), the total discontinuation of fluticasone propionate (study week 12), the start of the stable treatment phase (study week 18), and at the end of the randomized treatment period (study week 52). Home-based measurements were to be performed by patients each morning before administration of the study drug. Weekly mean values for $\mathrm{FEV}_{1}, \mathrm{FVC}$, and PEFR were calculated from the measurements taken in the 7 days prior to the day of the clinic visit for study weeks 6 , $12,18,27,36,45$, and 52 . For each week, the weekly mean $\mathrm{FEV}_{1}, \mathrm{FVC}$, and PEFR for each patient were calculated if there were at least four measurements during the 7-day week, with no imputation for missing data.

The study was performed in accordance with the Declaration of Helsinki, International Conference on Harmonisation Harmonised Tripartite Guideline for Good Clinical Practice, and local regulations. The protocol was approved by the ethics research board of the respective institutions (Supplementary material) and signed, informed consent was obtained from all patients.

\section{Spirometry}

Lung-function change was measured using spirometry, performed by trained staff during clinic visits and by the patients themselves each day throughout the 52-week study, following suitable training and receipt of full written instructions for use of the devices, including guidance for the washout of pulmonary medications and other restrictions. Each patient used the same portable, battery operated, ultrasound, transit-time-based electronic spirometer that was assigned to them for the duration of the study (EasyOne ${ }^{\circledR}$; ndd Medical Technologies, Chelmsford, MA, USA) for both home-based and in-clinic measurements. The EasyOne ${ }^{\circledR}$ spirometer has a screen that can display text and provides automated feedback to the patient in text form with the aim of improving the quality of test maneuvers. The device has no moving parts and has been shown to maintain accuracy for at least 4 years without the need for recalibration. ${ }^{10}$

For in-clinic spirometry testing, patients were required to have observed medication washout procedures (see below in this section) and to be comfortably seated upright with a nose clip in place. Pulmonary function testing was to begin 
at the same time of day, that is, between 7.00 am and 10.00 am, with a maximum difference of \pm 30 minutes allowed between the start of tests on different test days. Patients were to have abstained from salmeterol administration (during the previous 12 hours), tiotropium (24 hours), fluticasone propionate (morning dose at visit 3 , week $0=$ baseline), inhaled short-acting $\beta$-agonists ( 8 hours), and long-acting (48 hours) and short-acting (24 hours) theophylline preparations prior to testing. Patients were also asked to refrain from strenuous exercise within 12 hours prior to in-clinic spirometry, from smoking within 30 minutes of testing, and from caffeinecontaining or ice-cold drinks before spirometry on test days. The best of three (maximum five) efforts meeting American Thoracic Society (ATS) criteria was defined as the highest $\mathrm{FEV}_{1}, \mathrm{FVC}$, and PEFR value, respectively (therefore, the highest $\mathrm{FEV}_{1}$ value could have come from a different maneuver to that yielding the highest FVC or PEFR value).

For the home-based spirometric measurements, patients were provided with the same device used for in-clinic spirometry (EasyOne ${ }^{\circledR}$; ndd Medical Technologies). Patients were issued with the spirometers and trained at the randomization visit, and received full written instructions for the use of the devices, including guidance for the washout of pulmonary medications and other restrictions. Patients were asked to perform home-based spirometry prior to taking their medication every morning after the randomization visit until the end of treatment, except for the clinic visits at study weeks $6,12,18$, and 52. Home-based lung-function data were collected using the EasyOne ${ }^{\circledR}$ device with a specially developed home-monitoring firmware, with data retrieval occurring in-clinic. Data were imported using a special interface and software developed by BioMedical Systems (St Louis, MO, USA) and a central over-read of all lung-function data was performed by a pulmonologist, who graded it for acceptability according to ATS and European Respiratory Society (ERS) criteria. ${ }^{11}$ Patients performed multiple efforts each day and data from up to three maneuvers of acceptable quality per patient per day were used in the analysis. For each day, the highest $\mathrm{FEV}_{1}, \mathrm{FVC}$, and PEFR values were selected for the patient, each of which may have come from different maneuvers of acceptable quality. All spirometric equipment and techniques used were in accordance with ATS and ERS recommendations. ${ }^{11}$

\section{Statistics}

Data are presented as mean and standard deviation (SD) or standard error. The weekly mean $\mathrm{FEV}_{1}, \mathrm{FVC}$, and PEFR were defined as the mean of the measurements taken during the 7 days prior to the clinic visit date, and data are reported for those patients with at least four measurements during those 7 days. For the calculation of change from baseline in weekly mean $\mathrm{FEV}_{1}, \mathrm{FVC}$, and PEFR as measured by home spirometry, the baseline measurement was the corresponding baseline in-clinic measurement. Changes from baseline in trough $\mathrm{FEV}_{1}$ and weekly mean $\mathrm{FEV}_{1}, \mathrm{FVC}$, and PEFR were analyzed using a restricted maximum likelihood-based repeated measures approach.

To determine the comparability of in-clinic and homebased spirometric data, a post hoc Bland-Altman analysis of trough and weekly mean $\mathrm{FEV}_{1}$ was performed to establish the level of agreement between these measurements. ${ }^{12}$ Separately for each visit (study weeks 6, 12, 18, and 52), the difference between the two results (ie, weekly mean homebased $\mathrm{FEV}_{1}$ minus clinic trough $\mathrm{FEV}_{1}$ ) was plotted against the mean of the two results, with reference lines added for the bias (mean difference) and limits of agreement (mean difference \pm 2 SDs).

\section{Results}

A total of 2,488 patients were randomized to study treatment and 2,485 patients were treated, with 2,027 patients completing the study. As described previously, dropout rates did not differ between the treatment groups. ${ }^{3}$ For the whole population of treated patients, mean (SD) adherence to homebased spirometry, defined as the percentage of days during randomized treatment that the patient provided acceptable home-based spirometry results, was $72.7 \%$ (28.7). A total of 1,830 patients $(73.8 \%)$ provided acceptable home-based spirometry data on at least $60 \%$ of the days they were receiving randomized treatment and 1,395 patients $(56.3 \%)$ provided acceptable data on at least $80 \%$ of the days.

Overall, baseline in-clinic spirometry data were available for 2,441 patients. Of these patients, 2,161 had at least one visit where both in-clinic trough $\mathrm{FEV}_{1}$ and the corresponding home-based weekly mean $\mathrm{FEV}_{1}$ were available for comparison. Baseline characteristics for these patients are presented in Table 1.

\section{Time course of lung-function changes measured at home}

Figure 1 shows the change from baseline in weekly mean $\mathrm{FEV}_{1}$ calculated from home-based spirometry data at study weeks $6,12,18,27,36,45$, and 52 . There was a $0.04 \mathrm{~L}(95 \%$ confidence interval $[\mathrm{CI}]-0.06,-0.02 ; P<0.0001)$ decrease in weekly mean $\mathrm{FEV}_{1}$ in the ICS-withdrawal group versus the ICS group starting at week 18 (ie, after ICS had been stopped completely). The treatment difference remained statistically significant at subsequent visits, ranging from $-0.04 \mathrm{~L}$ 
Table I Baseline demographic and clinical characteristics of patients providing data for at least one visit for both in-clinic trough FEV, and corresponding home-based weekly mean FEV (treated set)

\begin{tabular}{|c|c|c|c|}
\hline & $\begin{array}{l}\text { ICS } \\
(n=I, 080)\end{array}$ & $\begin{array}{l}\text { ICS withdrawal } \\
(n=I, 08 I)\end{array}$ & $\begin{array}{l}\text { Total } \\
(n=2,161)\end{array}$ \\
\hline \multicolumn{4}{|l|}{ Sex, n (\%) } \\
\hline Male & $869(80.5)$ & $891(82.4)$ & $\mathrm{I}, 760(8 \mathrm{I} .4)$ \\
\hline Female & $211(19.5)$ & $190(17.6)$ & $40 I(18.6)$ \\
\hline Mean (SD) age, years & $63.4(8.6)$ & $63.8(8.3)$ & $63.6(8.4)$ \\
\hline \multicolumn{4}{|l|}{ Race, n (\%) } \\
\hline Native American/Alaska native & $0(0.0)$ & $\mathrm{I}(0 . \mathrm{I})$ & $\mathrm{I}(<0 . \mathrm{I})$ \\
\hline Asian & $125(\mid 1.6)$ & $136(12.6)$ & $26 I(12.1)$ \\
\hline Black/African-American & $6(0.6)$ & $3(0.3)$ & $9(0.4)$ \\
\hline Hawaiian/Pacific Islander & $4(0.4)$ & $3(0.3)$ & $7(0.3)$ \\
\hline White & $884(81.9)$ & $878(8 \mid .2)$ & $\mathrm{I}, 762(8 \mathrm{I} .5)$ \\
\hline Missing & $6 I(5.6)$ & $60(5.6)$ & $|2|(5.6)$ \\
\hline Mean (SD) body mass index, $\mathrm{kg} / \mathrm{m}^{2}$ & $25.3(5.1)$ & $25.2(5.0)$ & $25.2(5.1)$ \\
\hline Mean (SD) COPD duration, years & $7.7(6.0)$ & $8.1(6.6)$ & $7.9(6.3)$ \\
\hline \multicolumn{4}{|l|}{ Smoking status, n (\%) } \\
\hline Ex-smoker & $702(65.0)$ & $734(67.9)$ & $\mathrm{I}, 463(66.5)$ \\
\hline Current smoker & $378(35.0)$ & $347(32.1)$ & $725(33.5)$ \\
\hline Mean (SD) smoking history, pack-years & $43.8(23.4)$ & $45.0(24.6)$ & $44.4(24.0)$ \\
\hline \multicolumn{4}{|l|}{ GOLD postbronchodilator, ${ }^{\mathrm{a}} \mathrm{n}(\%)$} \\
\hline I & $\mathrm{I}(0 . \mathrm{I})$ & $\mathrm{I}(0 . \mathrm{I})$ & $2(0.1)$ \\
\hline 2 & $5(0.5)$ & $2(0.2)$ & $7(0.3)$ \\
\hline 3 & $670(62.0)$ & $674(62.3)$ & $\mathrm{I}, 344(62.2)$ \\
\hline 4 & $401(37.1)$ & $404(37.4)$ & $805(37.3)$ \\
\hline Missing & $3(0.3)$ & $0(0.0)$ & $3(0.1)$ \\
\hline \multicolumn{4}{|l|}{ Mean (SD) baseline lung function ${ }^{\mathrm{b}}$} \\
\hline $\mathrm{FEV}_{1}, \mathrm{~L}$ & $0.97(0.36)$ & $0.99(0.36)$ & $0.98(0.36)$ \\
\hline $\mathrm{FEV}, \%$ predicted & $34.3(10.9)$ & $34.6(10.6)$ & $34.46(10.8)$ \\
\hline FVC, L & $2.43(0.72)$ & $2.50(0.73)$ & $2.47(0.73)$ \\
\hline $\mathrm{FEV}_{1} / \mathrm{FVC}, \%$ & $43.1(11.6)$ & $42.6(11.7)$ & $42.8(11.7)$ \\
\hline PEFR, L/s & $3.30(1.21)$ & $3.35(1.20)$ & $3.32(1.21)$ \\
\hline
\end{tabular}

Notes: aAt screening; '

Abbreviations: COPD, chronic obstructive pulmonary disease; $\mathrm{FEV}_{\text {, }}$, forced expiratory volume in I second; FVC, forced vital capacity; GOLD, Global initiative for chronic Obstructive Lung Disease; ICS, inhaled corticosteroid; PEFR, peak expiratory flow rate; SD, standard deviation.

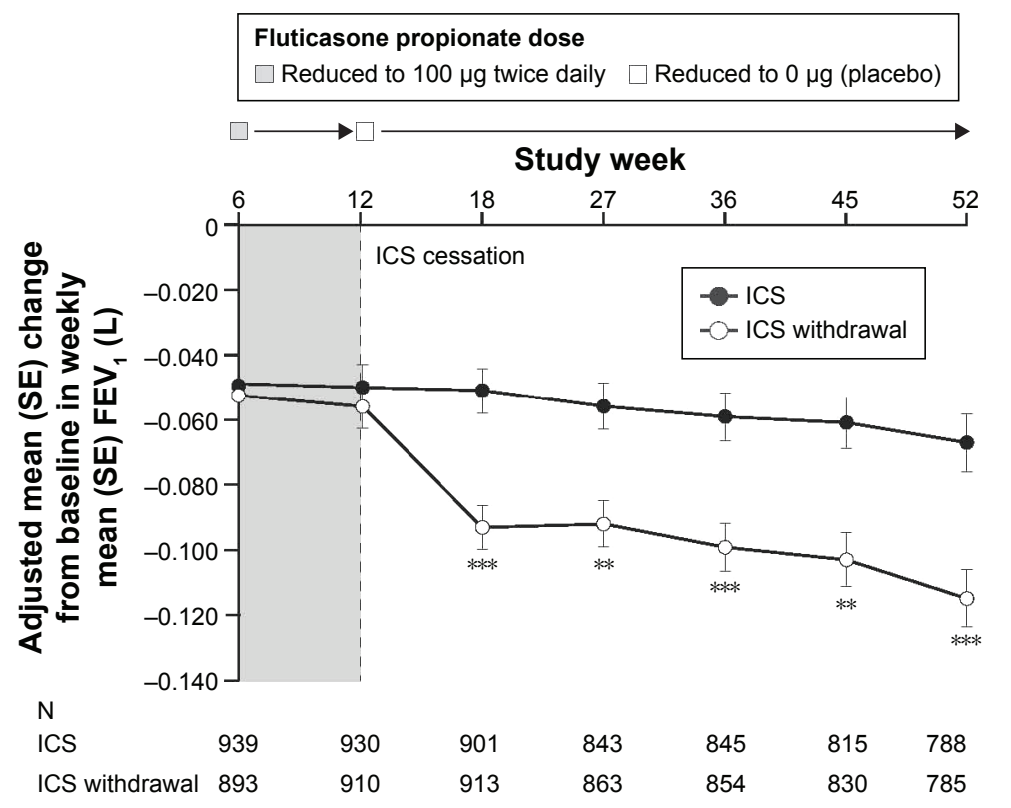

Figure I Adjusted mean (SE) changes from baseline in weekly mean ${ }^{\mathrm{a}} \mathrm{FEV}$, values derived from home-based spirometric data.

Notes: a Mean of the daily home-based $F E V$, values recorded in the week prior to the clinic visit, calculated if $\geq 4$ of the 7 days had non-missing measurements. $* * P<0.00$ I; $* * * P \leq 0.000$ I vs ICS; restricted maximum-likelihood repeated measures model; baseline values $970 \mathrm{~mL}$ for ICS, $98 \mathrm{I} \mathrm{mL} \mathrm{for} \mathrm{ICS} \mathrm{withdrawal.} \mathrm{Total} \mathrm{number} \mathrm{of} \mathrm{patients} \mathrm{included}$ in the analysis with baseline and $\geq 4$ measurements in the week prior to $\geq I$ of the clinic visits was 2,237 (I, II8 in the ICS group and I, II 9 in the ICS-withdrawal group). Abbreviations: $\mathrm{FEV}_{1}$, forced expiratory volume in I second; ICS, inhaled corticosteroid; SE, standard error. 
Table 2 Change from baseline in home-based measurements of on-treatment weekly mean FVC

\begin{tabular}{|c|c|c|c|c|}
\hline & \multirow[t]{2}{*}{ Treatment } & \multirow{2}{*}{$\begin{array}{l}\text { Adjusted } \\
\text { mean, L }\end{array}$} & \multicolumn{2}{|c|}{ Comparison vs ICS } \\
\hline & & & $\begin{array}{l}\text { Adjusted mean } \\
\text { difference, } L\end{array}$ & $95 \% \mathrm{Cl}$ \\
\hline \multirow[t]{2}{*}{ Study week 6} & ICS & -0.12 & & \\
\hline & ICS withdrawal & -0.09 & 0.03 & $-0.02,0.08$ \\
\hline \multirow[t]{2}{*}{ Study week 12} & ICS & -0.11 & & \\
\hline & ICS withdrawal & -0.11 & 0.01 & $-0.04,0.05$ \\
\hline \multirow[t]{2}{*}{ Study week 18} & ICS & -0.12 & & \\
\hline & ICS withdrawal & -0.12 & 0.00 & $-0.05,0.05$ \\
\hline \multirow[t]{2}{*}{ Study week 27} & ICS & -0.12 & & \\
\hline & ICS withdrawal & -0.15 & -0.02 & $-0.07,0.02$ \\
\hline \multirow[t]{2}{*}{ Study week 36} & ICS & -0.14 & & \\
\hline & ICS withdrawal & -0.16 & -0.02 & $-0.07,0.03$ \\
\hline \multirow[t]{2}{*}{ Study week 45} & ICS & -0.14 & & \\
\hline & ICS withdrawal & -0.17 & -0.03 & $-0.08,0.02$ \\
\hline \multirow[t]{2}{*}{ Study week 52} & ICS & -0.16 & & \\
\hline & ICS withdrawal & -0.20 & -0.04 & $-0.09,0.01$ \\
\hline
\end{tabular}

Note: $P>0.05$ for all treatment differences (not significant).

Abbreviations: $\mathrm{CI}$, confidence interval; FVC, forced vital capacity; ICS, inhaled corticosteroid.

$(95 \% \mathrm{CI}-0.06,-0.02 ; P<0.001)$ at study week 27 to $-0.05 \mathrm{~L}$ (95\% CI $-0.07,-0.02 ; P<0.0001)$ at study week 52 for the ICS-withdrawal group.

For weekly mean FVC, no significant differences between treatment groups were observed at any time point, but there were numerically lower FVC values in the ICS-withdrawal group toward the end of treatment (Table 2). Changes from baseline in weekly mean PEFR were generally consistent with the time course of weekly mean $\mathrm{FEV}_{1}$, with comparable values for both treatment groups at study weeks 6 and 12, and a greater reduction in PEFR in the ICS-withdrawal group at study week $18(P<0.001)$ (Table 3$)$. This difference remained significant up to study week $52(P<0.001)$.

\section{Level of agreement between FEV, values measured at home and in the clinic}

The Bland-Altman plot of the values from all four visits (Figure 2) shows that there was a mean difference of $-0.05 \mathrm{~L}$ between the weekly mean $\mathrm{FEV}_{1}$ values (calculated from homebased spirometry data obtained in the weeks immediately prior to the clinic visits) and the corresponding $\mathrm{FEV}_{1}$ values obtained in the clinic (limits of agreement $-0.37,0.27 \mathrm{~L}$ ).

Table 3 Change from baseline in home-based measurements of on-treatment PEFR

\begin{tabular}{|c|c|c|c|c|}
\hline & \multirow[t]{2}{*}{ Treatment } & \multirow{2}{*}{$\begin{array}{l}\text { Adjusted } \\
\text { mean, L/s }\end{array}$} & \multicolumn{2}{|c|}{ Comparison vs ICS } \\
\hline & & & $\begin{array}{l}\text { Adjusted mean } \\
\text { difference, L/s }\end{array}$ & $95 \% \mathrm{Cl}$ \\
\hline \multirow[t]{2}{*}{ Study week 6} & ICS & -0.23 & & \\
\hline & ICS withdrawal & -0.23 & -0.00 & $0.07,0.07$ \\
\hline \multirow[t]{2}{*}{ Study week 12} & ICS & -0.27 & & \\
\hline & ICS withdrawal & -0.29 & -0.02 & $-0.09,0.05$ \\
\hline \multirow[t]{2}{*}{ Study week 18} & ICS & -0.30 & & \\
\hline & ICS withdrawal & -0.44 & $-0.14 * *$ & $-0.2 \mathrm{I},-0.07$ \\
\hline \multirow[t]{2}{*}{ Study week 27} & ICS & -0.32 & & \\
\hline & ICS withdrawal & -0.43 & $-0.11 *$ & $-0.19,-0.04$ \\
\hline \multirow[t]{2}{*}{ Study week 36} & ICS & -0.35 & & \\
\hline & ICS withdrawal & -0.47 & $-0.12^{*}$ & $-0.20,-0.04$ \\
\hline \multirow[t]{2}{*}{ Study week 45} & ICS & -0.37 & & \\
\hline & ICS withdrawal & -0.49 & $-0.12^{*}$ & $-0.20,-0.04$ \\
\hline \multirow[t]{2}{*}{ Study week 52} & ICS & -0.38 & & \\
\hline & ICS withdrawal & -0.54 & $-0.16 * *$ & $-0.25,-0.07$ \\
\hline
\end{tabular}

Notes: $* P<0.01 ; * * P<0.001$.

Abbreviations: $\mathrm{Cl}$, confidence interval; ICS, inhaled corticosteroid; PEFR, peak expiratory flow rate. 


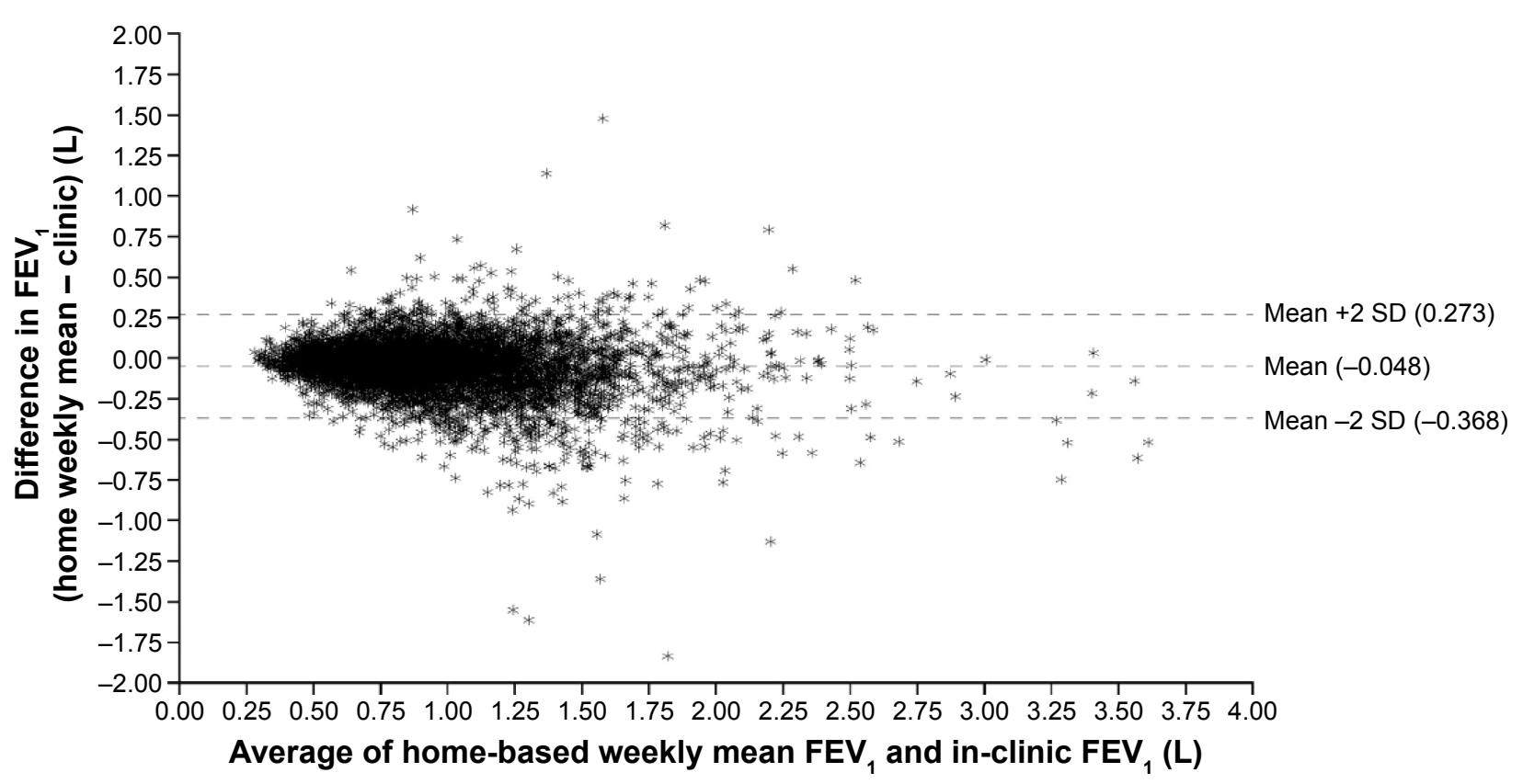

Figure 2 Bland-Altman analysis demonstrating the agreement between in-clinic and home-based spirometry results across all visits. Abbreviations: $\mathrm{FEV}_{1}$, forced expiratory volume in I second; SD, standard deviation.

For the individual study week visits $6,12,18$, and 52 , the mean differences (limits of agreement) between homebased and in-clinic spirometry were $-0.04 \mathrm{~L}(-0.35$, $0.27 \mathrm{~L}),-0.04 \mathrm{~L}(-0.36,0.28 \mathrm{~L}),-0.05 \mathrm{~L}(-0.35,0.25 \mathrm{~L})$, and $-0.06 \mathrm{~L}(-0.42,0.30 \mathrm{~L})$, respectively (Figure 3$)$.

\section{Discussion}

Home-based spirometry confirms the in-clinic $\mathrm{FEV}_{1}$ changes described previously, ${ }^{3}$ with an immediate lung-function decrease after complete ICS withdrawal and treatment differences reaching significance from study week 18 onward. ${ }^{13}$ In addition, we demonstrated that PEFR was also significantly reduced after complete ICS withdrawal. We found home-based spirometry to be a practical and reliable way to monitor $\mathrm{FEV}_{1}$, with agreement observed with the values measured in the clinic and without bias from differences in the degree of impairment.

Our initial concern that lack of supervision at home might compromise the quality of the results obtained was addressed by the consistent level of agreement between the home-based and in-clinic values (performed using the same equipment). Although the limits of agreement were wide and there were large differences between home-based and in-clinic measurements in individual patients, the BlandAltman analysis showed good overall agreement, ${ }^{14}$ both across all visits and for each individual visit. There was a consistent difference between the values recorded in the clinic and at home, which may be the result of suboptimal effort in the latter unsupervised recordings. However, by selecting the highest lung-function values for each day, using only acceptable data as determined by central review by a pulmonologist grading the data according to ATS/ERS criteria, and using the mean weekly value to account for variability across individual days, we reduced the impact of suboptimal efforts on our analysis. Additionally, the offset value did not change over time, supporting the reliability of home spirometry as a tool for studying the time course of lung-function changes (Figure 3). Together with the consistent home-based lung-function analysis, these findings confirm both the feasibility and reasonable accuracy of home-based spirometry in COPD studies, even for studies with 1-year duration. Adherence to home spirometry was within the range observed for adherence to study medication for clinical trials of 1-year or longer duration; $;{ }^{15}$ therefore, we believe our results are encouraging for the use of home spirometry even in the real-life setting. However, it should be acknowledged that motivation and training will need to be provided when applying home spirometry outside of a clinical trial setting.

Other studies evaluating home-based spirometry using portable spirometers have reported a similar acceptable agreement with in-clinic measurements, with mean differences in $\mathrm{FEV}_{1}$ values ranging from $-0.02 \mathrm{~L}$ to $-0.11 \mathrm{~L}$ from (unsupervised) home measurements. ${ }^{6-8}$ This is likely to reflect the inclusion of a number of suboptimal tests in the weekly mean data. 


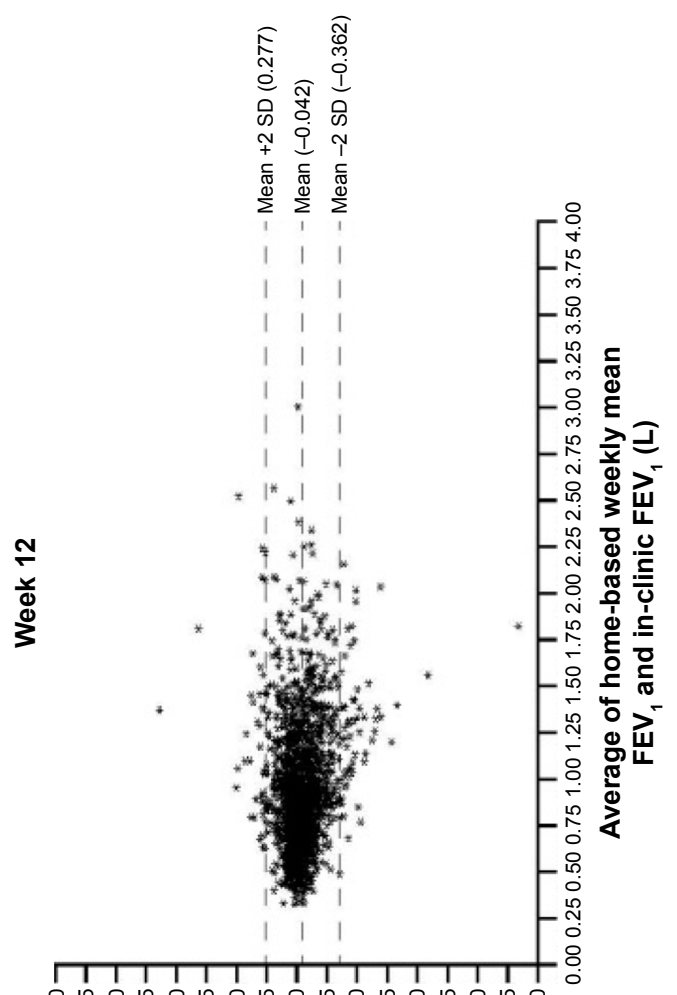

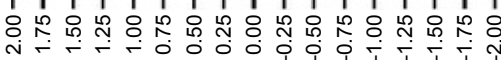

(7) (ग!ฺ!|ग - uеәш КІуәәм әшоч)

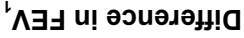

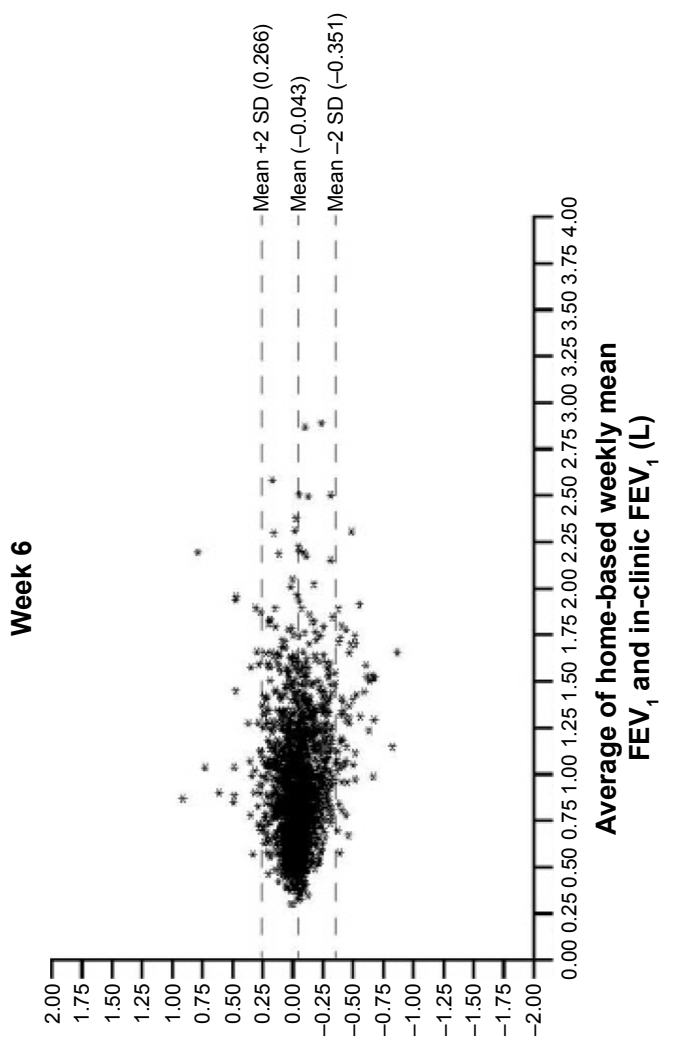

(7) (ग!ฺ!ן - ueәш КІчәәәм әшоч) $\Lambda \exists \exists$ น! әэนәдән!

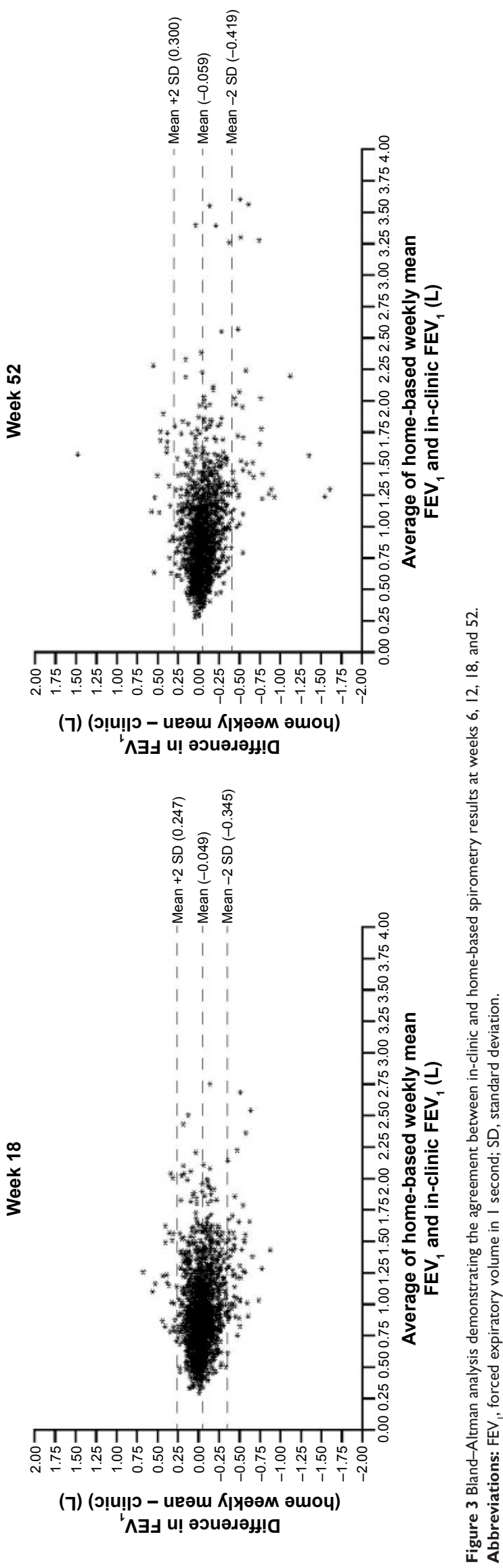

International Journal of COPD 2016:I I 
Our data suggest that home-based spirometry is a reliable tool and may prove useful in other proof-of-concept clinical studies. Daily spirometry performed at home could provide a powerful tool to characterize small changes in $\mathrm{FEV}_{1}$ in a large patient population. However, the value of homebased spirometry for detecting changes of this magnitude in individual patients is more questionable, as such changes might fall within the range of day-to-day variability of lungfunction assessment. ${ }^{16}$

\section{Author contributions}

All authors contributed toward data analysis and interpretation, drafting and revising the paper and agree to be accountable for all aspects of the work.

\section{Acknowledgments}

This work was supported by Boehringer Ingelheim Pharma $\mathrm{GmbH} \& \mathrm{Co}$. KG. Medical writing assistance was provided by Marshall Naden, PhD, of Complete HealthVizion, which was contracted and compensated by Boehringer Ingelheim Pharma GmbH \& Co. KG.

\section{Disclosures}

RR-R reports grants from Almirall and Menarini, and personal fees for advisory boards and lectures from AstraZeneca, Boehringer Ingelheim, Mylan, Takeda, Pearl Therapeutics, Teva, Almirall, Ferrer, Menarini, and Novartis outside of the submitted work. KT is an employee of, BD is a former employee of and HF is contracted to, Boehringer Ingelheim. HW reports consulting fees and compensation for his institution during the conduct of the study from Boehringer Ingelheim related to the submitted work, and participation in advisory boards for Almirall, AstraZeneca, Boehringer Ingelheim, and GlaxoSmithKline, in lectures for Almirall, AstraZeneca, Boehringer Ingelheim, BerlinChemie, GlaxoSmithKline, Novartis, and Chiesi, and congress travel support from GlaxoSmithKline and Novartis outside of the submitted work. His institution has also received compensation for the conduct of clinical studies from Almirall, AstraZeneca, Boehringer Ingelheim, GlaxoSmithKline, Novartis, Chiesi, Takeda, AB2 Bio, Bayer, and InterMune outside of the submitted work. EFMW reports grants and personal fees from AstraZeneca, GlaxoSmithKline, and Novartis, and personal fees from Takeda, Pfizer, and Boehringer Ingelheim outside of the submitted work. HM reports consulting fees and compensation for his institution during the conduct of the study from Boehringer
Ingelheim related to the submitted work, and participation in advisory boards for Almirall, AstraZeneca, Boehringer Ingelheim, Berlin-Chemie, and Novartis, and in lectures for Almirall, AstraZeneca, Boehringer Ingelheim, BerlinChemie, Novartis, and Chiesi outside of the submitted work. His institution has also received compensation for the conduct of clinical studies from Almirall, AstraZeneca, Boehringer Ingelheim, GlaxoSmithKline, Novartis, Chiesi, Takeda, AB2 Bio, Bayer, and InterMune outside of the submitted work. PMAC reports a study grant from Boehringer Ingelheim related to the submitted work, and a grant from GlaxoSmithKline and speaker fees and consultancy for AstraZeneca, Takeda, and Boehringer Ingelheim outside of the submitted work. The authors report no other conflicts of interest in this work.

\section{References}

1. Menezes AM, Perez-Padilla R, Jardim JR, et al. Chronic obstructive pulmonary disease in five Latin American cities (the PLATINO study): a prevalence study. Lancet. 2005;366(9500):1875-1881.

2. Buist AS, McBurnie MA, Vollmer WM, et al. International variation in the prevalence of COPD (the BOLD Study): a population-based prevalence study. Lancet. 2007;370(9589):741-750.

3. Magnussen H, Disse B, Rodriguez-Roisin R, et al. Withdrawal of inhaled glucocorticoids and exacerbations of COPD. $N$ Engl J Med. 2014;371(14):1285-1294.

4. Vestbo J, Pauwels R, Anderson JA, Jones P, Calverley P; TRISTAN study group; Early onset of effect of salmeterol and fluticasone propionate in chronic obstructive pulmonary disease. Thorax. 2005;60(4): 301-304.

5. Welte T, Miravitlles M, Hernandez P, et al. Efficacy and tolerability of budesonide/formoterol added to tiotropium in patients with chronic obstructive pulmonary disease. Am J Respir Crit Care Med. 2009;180(8): 741-750.

6. Brouwer AFJ, Roorda RJ, Brand PLP. Comparison between peak expiratory flow and $\mathrm{FEV}_{1}$ measurements on a home spirometer and on a pneumotachograph in children with asthma. Pediatr Pulmonol. 2007; 42(9):813-818.

7. Morlion B, Knoop C, Paiva M, Estenne M. Internet-based home monitoring of pulmonary function after lung transplantation. Am J Respir Crit Care Med. 2002;165(5):694-697.

8. Mortimer KM, Fallot A, Balmes JR, Tager IB. Evaluating the use of a portable spirometer in a study of pediatric asthma. Chest. 2003;123(6): 1899-1907.

9. Magnussen H, Watz H, Kirsten A, et al. Stepwise withdrawal of inhaled corticosteroids in COPD patients receiving dual bronchodilation: WISDOM study design and rationale. Respir Med. 2014;108(4): 593-599.

10. Skloot GS, Edwards NT, Enright PL. Four-year calibration stability of the EasyOne portable spirometer. Respir Care. 2010;55(7): 873-877.

11. Miller MR, Hankinson J, Brusasco V, et al. Standardisation of spirometry. Eur Respir J. 2005;26(2):319-338.

12. Bland JM, Altman DG. Agreement between methods of measurement with multiple observations per individual. J Biopharm Stat. 2007;17(4): 571-582.

13. Magnussen H, Tetzlaff K, Bateman ED, et al. Lung function changes over time following withdrawal of inhaled corticosteroids in patients with severe COPD. Eur Respir J. 2016;47(2):651-654. 
14. Bland JM, Altman DG. Statistical methods for assessing agreement between two methods of clinical measurement. Lancet. 1986;1(8476): 307-310.

15. Vestbo J, Anderson JA, Calverley PM, et al. Adherence to inhaled therapy, mortality and hospital admission in COPD. Thorax. 2009; 64(11):939-943.
16. Calverley PM, Albert P, Walker PP. Bronchodilator reversibility in chronic obstructive pulmonary disease: use and limitations. Lancet Respir Med. 2013;1(7):564-573.

International Journal of COPD

\section{Publish your work in this journal}

The International Journal of COPD is an international, peer-reviewed journal of therapeutics and pharmacology focusing on concise rapid reporting of clinical studies and reviews in COPD. Special focus is given to the pathophysiological processes underlying the disease, intervention programs, patient focused education, and self management protocols.
Dovepress

This journal is indexed on PubMed Central, MedLine and CAS. The manuscript management system is completely online and includes a very quick and fair peer-review system, which is all easy to use. Visit http://www.dovepress.com/testimonials.php to read real quotes from published authors.

Submit your manuscript here: http://www.dovepress.com/international-journal-of-chronic-obstructive-pulmonary-disease-journal 